\section{HAVE YOU TREATED MARK MANNING?}

Mark Manning, born 14 October 1959, of 37 Kings Court, Brighton Road, Lancing, West Sussex, BN15 8EY, was reported missing by his sister on 22 April 2014. Mr Manning was last seen alive on 19 April 2014. Sussex Police suspect that Mr Manning has been murdered but his body has not yet been found.

DC Laura Carron of Sussex and Surrey Major Crime Team would like all dental professionals to check their records for the period 1 January 2014 to present to establish if Mr Manning has registered or attended. Please could all professionals also check their records for the name Michael Stone with a birth date of 5 November 1960, as Mr Manning has used these details in the past.

DC Laura Carron can be contacted by calling 07795646337 or by emailing laura.carron@ sussex.pnn.police.uk.

\section{DIARY SPOTLIGHT \\ Introduction to \\ Lingual Orthodontics: a one-day course for postgrads and orthodontic therapists Date: 5 September 2014, 9 am-4 pm Venue: Run by BLOS at BOS HO, 12 Bridewell Place, EC4V 6AP www.blos.co.uk/meetings.php}

British Society for Paediatric Dentistry annual conference: Evolution or Revolution Date: 17-19 September 2014 Venue: Royal College of Physicians, London

www.bspdconference.org

BDIA Dental Showcase

Date: 9-11 October 2014

Venue: ExCeL, London

www.dentalshowcase.com

Lingual orthodontics study club by Seminars@38

Date: 12 November 2014

Venue: 38 Devonshire Street, W1G 60B, 6.30-9.30 pm www.blos.co.uk/meetings.php

\title{
OVERSEAS DENTISTS CROSS THE MOAT TO UK PRACTICE
}

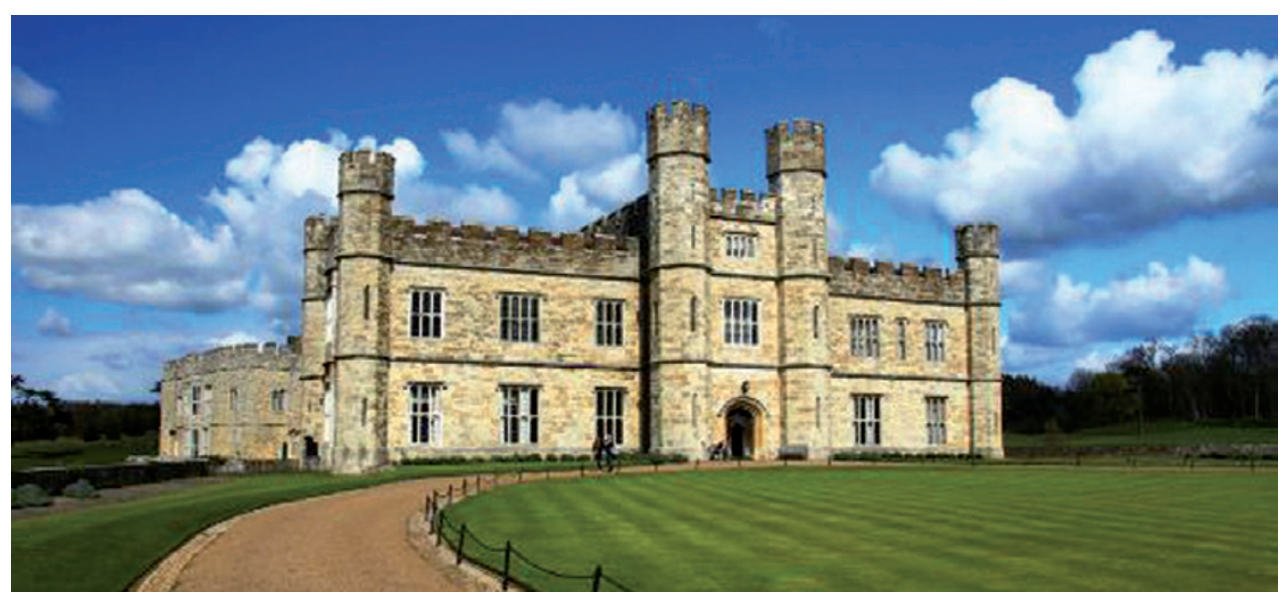

Leeds Castle in Kent raised its portcullis in June for a group of overseas-qualified dentists who are newly-registered with the General Dental Council (GDC), having completed the statutory exam.

The three-day event held at a beautiful English venue was arranged by Mr Adeel Khan, a practising GDP in East Sussex, who sought to provide a "pathway to success in dentistry' to delegates. Mr Khan followed the same route himself a few years ago and wanted to share his experience, specifically how to acquire an NHS performer number via the assessment route.

\section{BOOK REVIEW}

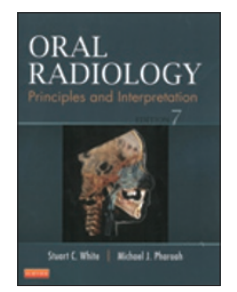

\section{ORAL RADIOLOGY: PRINCIPLES AND INTERPRETATION, 7TH EDITION \\ S. C. White, M. J. Pharoah \\ Elsevier \\ price £90.00; pp 696 \\ ISBN 9780323096331}

This is an essential read for dental practitioners wanting to comprehend the basic radiological principles of everyday dental care and to further interpret images produced with different modalities.

The book is broadly categorised into two parts: firstly the 'Principles' of radiology such as how ionising radiation interacts with biological matter, the radiographic manifestation of disease within oral and maxillofacial tissues and quality control. 'Interpretation of exposures' covers caries and periodontitis along with the radiographic manifestations of systemic disease states and conditions, malignancies, maxillofacial trauma and temporomandibular joint abnormalities. The use of radiology for implantology and forensics is also presented.

This edition has vast improvements on predecessors; two extra chapters detail CBCT, reflecting the advancement of technology and increasing incorporation into daily practice; and online test bank images supplement preparation for examinations.

The text has a clear objective to teach one to be thorough, careful and systematic when exposing and interpreting dental radiographic images. The authors
An interactive series of lectures and workshops was delivered over the three days and included topics such as associate contracts, vocational training equivalency, recordkeeping and medico-legal aspects, CPD, integration into UK practice, NHS regulations, communication skills and career progression via assessment and training available from the FGDP(UK).

provide an excellent resource with clinical relevance to common disease states, with a commensurate refreshment of knowledge of the complex anatomy of the facial skeleton.

The clarity of images, which are provided in colour for the first time in the title's publication, supplements the text to further exemplify the fundamentals of oral radiology. Although the authors and editorial board are predominantly based in the US, the nomenclature does not deter from the value of the text.

The book provides a means for clinicians to develop a quality control by comparing images to the gold standard in terms of geometry and contrast, subsequently furthering competency and thus attaining the maximal diagnostic yield possible when exposing to ionising radiation.

This is a valuable source of information that should be in the armamentarium of any dentist in training or wanting to develop their competence in oral radiology.

T. HUGHES 